No mercado internacional, aponta-se, como exemplo típico, em relação ao nosso país, a política de valorização do café. Enquanto éramos os principais fornecedores, pudemos impor o preço artificialmente estabelecido. A larga margem de lucro, que então ficava ao produtor nacional, induziu-o aumentar as áreas cultivadas, crescendo, assim, de ano para ano, a quantidade exportável. Essa miragem de lucro não haveria de ser sempre privilégio nosso e, por isso, aquelas regiōes cujas condições climáticas eram favoráveis a semelhante cultura, (Venezuela, Colúmbia, América Central e Antilhas) entraram a fazer o mesmo. Dentro em pouco, estávamos com produção sobreexcedente às exigências normais de nosso consumo e sem mercado externo, para escoá-la, porque tínhamos sido superados por êsses novos concorrentes, que se aproveitaram da valorização. Resultado disso, foi a inversão de vultosa soma, retirada do erário público, para a aquisição e retenção dos "stoks" e, por fim, a queima criminosa de milhóes de sacas de café.

Envolvido pela crise, que êle próprio suscitou, o govêrno, após já ter uma vez sacrificado a economia nacional, sacrificou-a, mais ainda, com mandar inutilizar lavouras e assumir as dívidas dos agricultores!... Se fôsse possível conhecer a cifra exata dêsses prejuízos, a simples lei-, tura dos números nos deixaria estarrecidos!

$\mathrm{E}$ 'por isso, que o professor LUIS BUDIN ( $\left.{ }^{45}\right)$ resumiu as conseqüências dessa política neste incisivo juízo: "Escândalo devido, em definitivo, à intervenção, desastrada, do Estado no domínio da oferta com o fim de dirigir os preços".

Não menos censurável é a ação dessas organizações nos outros setores da produção. O encarecimento das utilidades deve-se, em grande parte, aos tais Institutos e órgãos análogos. E' que a manutenção dêles é feita às expensas da produção, sôbre que se fazem recair as cognominadas taxas. A par disso, a pesada burocracia, o regime do papelório, dos vistos, licenças e quejandas formalidades, a que se submete o trânsito e a circulação das mercadorias, entorpecem, entravam e dificultam a livre negociação delas. Gêneros pobres, como a erva-mate e a mandioca são gravados com taxas excessivas, a pretexto de melhoria do produto ou coisa que valha. Mas aos pseudos favorecidos não volvem jamais, porque tôda arrecadação é absorvida na mantença custosa de tais autarquias.

Sofrem, assim, o comércio, que tem seus movimentos tolhidos, sofrem, por fim, os consumidores, sôbre os quais, em última instância, recaem todos êsses ônus, fundidos nos preços das utilidades.

Eis por que exige o comércio liberdade de movimento e adequada tutela jurídica.

Fora, daí, tôdas restrições são indébitas e contraproducentes.

(45) Mand. d'Èconomie Politique, 5.a ed. pgs. 282 e 2833.

\section{DE RETENÇÃO}

\author{
Armando Dias de Azevedo
}

Código de Processo Civil, decretado a 18 de setembro de 1939 (decreto-lei n..$^{\circ} 1.608$ ), a par de oportunas reformas, de há muito reclamadas pela consciência jurídica nacional, introduziu, ao arrepio da tra dic̃o do direito pátrio, sem a preparação doutrinária imprescindí位 vel, infelizes inovaçoes

exigem urgente revisão.

Já o legislador se viu obrigado, pelo decreto-lei n. de agôsto de 1942, a atende

alterações e retificações. Regula a matéria da
título IV do livro VIII.

Nêle encontramos, na redação primitiva, dois artigos que repumos antinômicos o - 992 e o 996 - o que levou os exegetas, à vista da regra de hermenêutica, que não admite se presumam contradiçõ no legislador, a se esforçarem no sentido de os conciliar.

O artigo 992 , conservado intato, assim estatui

"A execurão da sentença, que condene a entregar coisa certa, ou "A expécie, começará pela citação do réu para, no prazo de dez dias, que correrá em cartório, fazer a entrega, ou alegar a defesa" ( ${ }^{1}$ ).

O artigo 996, em sua primitiva redação, determinava:

"Se, dentro de cinco dias; o executado opuser embargos, o exeüente não poderá receber a coisa sem prestar caução".

Pela correcão do decreto-lei n. ${ }^{\circ} 4.565$, de 11 de agôsto de 1942 , preceitua agora o mencionado artigo 996 :

(1) 0 art. 955 do Código do Processo Civil e Comercial d de do Sul (lei no 05 de 16 de ianeiro de 1908), determinava: "Se a execucáo tiver por fazer a entrega dela". 
"Se, no prazo legal, o executado opuser embargos, o exeqüente não poderá receber a coisa sem prestar caução" ( $\left.{ }^{2}\right)$

" $\$$ único do artigo 996 ficou intato:

cutado, ou pelo terceiro, de indenizáveis, feitas de boa fé pelo exesó a receberá se depositar cuja posse fôr tirada a coisa, o exeqüente rito".

Êsse dispositivo, em sua primitiva redação, era a tortura dos tratadistas e comentadores, que se dividiam, apurar no estudo comparativo dos dividiam, - o quanto pudemos correntes, tôdas elas visando menos, em três ciliar aquêles dois dispositivos, em nossa opinião, incongruentes.

A primeira corrente opinava que havia duas espécies de prazos

A ela se filiava CARVALHO SANTOS, que, 1947 do Código de Processo Civil Brasileiro que, em sua edição de mentando ainda o texto de 1942, escrevia:

"Os comenta:

"Os comentadores do nosso Código de Processo procuram conciliar o artigo 992 com o que dispõe o artigo supra, da seguinte forma: " o prazo de dez dias, à que alude o artigo 992, é para que se apresente a defesa ou se deposite a cousa;

“- o prazo de cinco dias, a que se refere o texto supra, é pròpriamente para a oposição dos embargos, contando-se êle do dia em que
se efetivar o depósito" $\left({ }^{3}\right)$. De passagem,

De passagem, permita-se-nos ponderar que o artigo 992 não diz, que se apresente a defesa ou se deposite o prazo de dez dias "é para zer a entrega, ou alegar a defesa". Apesar dêsse êrro do comenta".

de acertar, que o levou a sentir a precaçamos justiça à sua intenção tanto assim que, logo abaixo, acrescentou.

"Essa interpretação,

a única admissível se não se quiser, antes, engenhosa, sendo mesmo tradição entre os dois dispositivos.

"Quer dizer: será de dez dias

em justificar o não poder dez dias o prazo para a defesa consistente plo, se ela pereceu no caso fortuito, etc.

\footnotetext{
(2) Na secção relativa aos embargos do executado, o Código do Processo Civil e
omercial do Estado do Rio Grande do Sul, em seu art

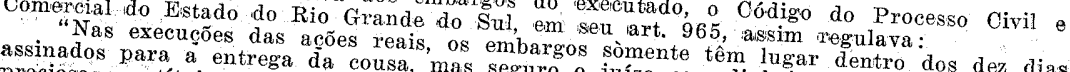
preciosas ou títulos e papéis de crédito equiivalentes júzo com dinheiro, ouro, prata dez dias "Depositando o executado a cousa, deverá o sentes.

(3) CARVALHO ". $\mathrm{X}$, pg. 256.
}

"De cinco dias será o prazo para embargos, depois de depositada a coisa, porque cai na regra geral de que cogita o artigo 1008 " $\left({ }^{4}\right)$

Outra corrente, considerando que a única defesa eram os embargos do executado, exigia a oposição dos embargos nos cincos primeiros dias".

Assim, ensinava o eminente Prof. JOÃO BONUMÁ, catedrático de Direito Judiciário Civil na Faculdade de Direito da Universidade do Rio Grande do Sul e Procurador Geral do Estado:

"A execução da sentença, que condene a entregar coisa certa, ou em espécie, começará pela citação do réu para, no prazo de 10 dias, que correrá em cartório, fazer a entrega, ou alegar defesa (Cód., art. 992). Essa defesa, que consistirá em embargos, sòmente poderá ser apresentada nos cinco primeiros dias do prazo, seguro o juízo, mediante o depósito da própria coisa sôbre que versar a execução (arts. 995 e 1009). Se o executado não entregar a coisa e deixar fluir o prazo sem opor embargos, ou se êstes forem julgados definitivamente improcedentes, expedir-se-á mandado para a imissão do exeqüente na posse dela, se se tratar de imóvel, ou mandado de busca e apreensão, se se tratar de móvel (art. 993). Mas, postos e recebidos os embargos, o exeqüente não poderá receber a coisa sem prestar caução (art. 996). Também não poderá recebê-la, quando o executado, ou terceiro em cujo poder estiver a coisa, tiver feito nela, de boa-fé, benfeitorias indispensáveis, sem depositar o valor das benfeitorias, arbitrado por perito (art. 996, § único)" $\left({ }^{5}\right)$.

O erudito mestre, para conciliar dispositivos, em nossa opinião tão incoerentes, à falta do elemento histórico da elaboração parlamentar, inexistente àquela época, chegava a reduzir o prazo para oposição dos embargos do executado.

A terceira corrente era categórica no considerar única defesa do executado os embargos, e, procurando, como as demais conciliar os dispositivos díspares dos arts. 992 e 996, fazia influir o tempo nos direitos do exeqüente e do executado, embora criticasse o que reputava rompimento com a tradição do direito brasileiro.

Assim, em seus Comentários ao Código de Processo Civil (edição da REVISTA FORENSE), o Desembargador AMÍLCAR DE CASTRO, ilustre professor da Faculdade de Direito da Universidade de Minas Gerais, escreveu:

"De falar o art. 992 em defesa no prazo de dez dias, e o art. 996 se referir a embargos do executado dentro de cinco dias, não se deve supor que na técnica dêsses dois artigos defesa e embargos sejam coisas diversas" $\left({ }^{6}\right)$.

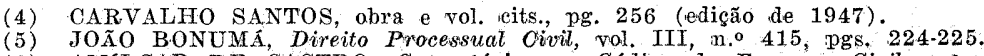

(6) AMfLCAR DE OASTRO, Oomentários ao Código de Processo Civil, vol. $\mathbf{X}$, T. 406 , pgs. $360-361$. 
E, mais adiante:

"De tal sorte, no art. 996, tem-se o tempo a influir nos direitos do exeqüente e do executado: se os embargos forem opostos nos primeiros. cinco dias do decêndio, o exeqüente não poderá receber a coisa sem prestar caução de restituição e às perdas e danos, se for móvel, ou aos frutos sòmente, se fôr imóvel. $E$ se os embargos forem opostos nos últimos cinco dias do decêndio, o exeqüente poderá receber a coisa sem prestar caução. A distinção, que não parece necessária, nunca foi do nosso direito.

"No caso de benfeitorias indenizáveis, feitas de boa fé pelo executado, ou pelo terceiro de cuja posse fôr tirada a coisa, para receber esta, o exeqüente deve depositar o valor das benfeitorias que fôr arbitrado por perito" $\left({ }^{7}\right)$.

Mais além, acrescenta:

"Pode, entretanto, o depósito ser apenas da diferença enitre a quantia em que foram arbitradas as benfeitorias e o valor dos frutos e danos que já tiverem sido liquidados, devidos pelo executado" (8).

Era o caso de, então, em face de tal dissídio de interpretações, se dizer: Grammatici certant...

E, como as dúvidas se avolumavam sôbre o alcance do dispositivo, tão profunda a discrepância dos doutos na exegese do texto legal, que o legislador modificou o art. 996, restabelecendo a tradição do direito pátrio, pela substituição de "dentro de cinco dias" por "no prazo legal", unificando, assim, os prazos e cortando cerce qualquer dúvida que pudesse subsistir sôbre a identidade, em tema de execuções, entre defesa (art. 992) e embargos (art. 996):

Por isso, DE PLÁCIDO E SILVA, tomando conhecimento da modificação, escreveu novos comentários, nos seguintes têrmos, na 3. ${ }^{a}$ edição de seu volume $\mathrm{V}$ de Comentários ao Código de Processo Civil:

"O art. 996, consoante já anotámos, era redigido, originàriamente, de forma diferente. Em princípio, aludia ao prazo de cinco dias, havendo essa redação sido modificada pelo art. 45 do decreto-lei 4.565 de 1942, que a substituiu pela no prazo legal.

"Nas execuções por quantia certa, para as quais é aplicável a norma instituída pelo art. 996, o prazo para embargar correu sempre junto com o prazo para entregar a coisa, ou para alegar defesa, que pode ser licitamente deduzida por via de embargos.

"Por essa razão, o prazo legal referido no art. 996 é precisamente o que se estabelece no art. 992, pelo qual se assegura ao executado o poder de opor-se à pretensão do exequiente, se lhe assistem direitos para essa oposição.

(7) AMILCAR DE CASTRO, o, c, vol. $\mathrm{X}$, no 406407 , po. 361 .
Revista da Faculdade de Direito de Pôrto Alegre

"Assim, o prazo legal fixado no art. 996 é o mesmo prazo de dez dias assinados para a defesa, conforme se expressa no art. 992" ( $\left.{ }^{9}\right)$.

Com relação à hipótese de benfeitorias indenizáveis, a que alude o \$ único do art. 996, merece meditada a magnífica lição que, no mesmo volume, duas páginas além, nos dá DE PLÁCIDO E SILVA:

"Conforme se infere do $§$ único do art. 996, o que aliás é de regra geralmente aceita, o devedor se encontra com o direito de embargar o cumprimento da obrigação, tanto como a entrega da coisa, se tem a reclamar benfeitorias promovidas em benefício do credor ou despesas feitas à sua conta.

"No caso em espécie, isto é, na execução para entrega de coisa certa, não cabe ao executado nem ao terceiro retê-la, como se institui no art. 1012, a pretexto de benfeitorias. E' obrigatório o depósito dela, para dedução dos embargos, em que se aleguem benfeitorias indenizáveis.

"Neste particular, são precisos os têrmos do art. 995. Os embargos por benfeitorias indenizáveis são admitidos depois que a coisa foi entregue em juízo, para o devido depósito, desde que essa espécie não se pode furtar à exigência imposta para o recebimento dos embargos, pelo executado, ou pelo terceiro.

"E êles se mostram direito certo do executado, como do terceiro adquirente, em poder de quem a coisa se encontrava, para haver do exeqüente o valor das benfeitorias indenizáveis, e feitas de boa fé.

"Benfeitorias indenizáveis se entendem, assim, as que se fizerem em benefício da coisa, evidenciadas por sua necessidade. Serão despesas úteis, que fundamentam a sua indenização, não despesas voluptuárias, cuja promoção não encontraria justificativas.

"Mas, além de comprovadas e justificadas, as benfeitorias indenizáveis terão seu valor arbitrado por perito designado pelo juiz.

"E procedente o pedido, não poderá o exeqüente levantar a coisa para que ingresse em sua posse e domínio, sem que deposite, por seu turno, o valor dessas benfeitorias.

"E' mais uma restrição ao direito do exeqüente a respeito do levantamento da coisa depositada. Desde', porém, que paga o valor arbitrado, livra-se do encargo, e pode pedir que se lhe entregue a coisa" $\left({ }^{10}\right)$.

Portanto, não pode o executado usar, de modo absoluto, do direito de retenção previsto no art. 516 do Código Civil, mas sim, caso se configure a hipótese neste regulada, depois de seguro o juizo, pode, por via de embargos, formular o pedido de retenção por benfeitorias, como ensina DE PLÁCIDO E SILVA:

(9) DE PLÁCIDO E SILVA, Comentários ao Código de Processo Oivil, vol. V, n. ${ }^{\circ}$ (10) pg. $1957,3 a^{a}$ edição.

$7-$ R. F. D 
“.. além dos embargos que lhe são facultados como matéria de defesa no art. 1010, pode ainda opor embargos por benfeitorias" (11).

O mesmo DE PLÁCIDO E SILVA é decisivo, quando acrescenta, mais adiante:

"Convém assinalar, ainda, que o pedido de indeniwação por benfeitorias, mesmo que se formule no estilo de embargos, não libera o executado do depósito prévio da coisa, que dever restituir ou entregar" $\left({ }^{12}\right)$.

O que deve, por conseguinte, fazer o executado é depositar o objeto do litígio e formular seus embargos de tôda a matéria porventura cabível, inclusive benfeitorias, pois o art. 995 do Código de Processo Civil assim o ordena:

"Os embargos do executado, ou do terceiro, não serão admitidos sem estar prèviamente seguro o juízo, mediante o depósito da coisa sôbre que correr a execução".

E' essa também a lição do Prof. ENRICO TULLIO LIEBMAN, catedrático da Universidade de Pávia, profundo conhecedor de nossa processualística:

"Depois de seguro o juízo e no prazo mencionado de dez dias, o executado, poderá opor embargos (arts. 995 e 996 do Código de Processo Civil), nos quais poderá alegar a matéria indicada no art. 1010 do Código de Processo Civil e a retenção por benfeitorias (art. 1012). Em caso de benfeitorias, o exeqüente só receberá a coisa depositandolhe o valor, arbitrado por perito (art. $996, \S$ único)” $\left({ }^{13}\right)$.

E' certo que o Prof. JORGE AMERICANO, catedrático da Faculdade de Direito da Universidade de S. Paulo, comentando o art. 995 do Código de Processo Civil, diz que podem "ser discutidos independente de caução ou fiança à restituição dela os embargos de retenção por benfeitorias" ( $\left.{ }^{14}\right)$, mas tal afirmativa vem desacompanhada de qualquer argumentação, quanto mais de amparo em texto legal. E' uma distinção que o ilustre mestre faz, sem que a lei a faça. Ubi lex non distinguit, nec nos distinguere debemus.

E' certo também que CARVALHO SANTOS sustenta que, em caso de embargos por benfeitorias, não cabe a exigência de segurança do juízo, porquê, em seu entender, "eqüivaleria a tornar ilusório o direito de retenção, assegurado na lei civil".

11) DE PLÁACIDO E SILVA, o. c., vol. V, n.0 2668, pg. 1999.

(12) DE PLÁACIDO E SILV.A, o. c., vol. V, n. ${ }^{\circ} 2669$, pgs. $1999-2000$

(13) ENRICO TULIIO LITEBMAN, Processo das execucôes, m.o 95, pgrs. 331-332. vol. IV, pg. 349 .
Não tem, porém, razão o tão citado comentador, pois, como vimos acima, nas lições de DE PLÁCIDO E SILVA e de TULLIO LIEBMAN, o executado, depois de segurar o juízo, é que pode pedir a retenção por benfeitorias.

Aliás, o bom senso está a indicar que seria perigoso permitir o direito de retenção com a simples alegação de benfeitorias, sem prévia segurança do juízo, porque poderia levar o executado a abusar de tal direito, prolongando sua retenção do objeto do litígio. Bastaria que - executado fizesse qualquer absurda alegação de benfeitorias, que só poderia vir a ser destruída pela prova produzida, mas, enquanto o executado usasse e abusasse de todos os recursos do Código - apelação, agravo, embargos de nulidade e infringentes do julgado, embargos declaratórios e, mesmo, os de efeito meramente devolutivo, como revista e recurso extraordinário - estaria o vencedor da ação privado da posse da cousa, continuando esta em poder do vencido.

O eminente Desembargador LOPES DA COSTA, luzeiro do Tribunal de Justiça do Estado de Minas, em seu Direito Processual Civil Brasileiro, vol. IV, n. ${ }^{\circ} 101$, pg. 72 , após ensinar que, na execução, "tais defesas devem ser articuladas como preliminar de outra matéria, mas sob forma de embargos, embora, quando a natureza do processo o exija, se obedeça depois ao processo especial das exceções processuais, como sucederá com a de suspeição por exemplo", acrescenta:

"O processo executivo deve ser, tanto quanto possível, rápido. A falta de voluntária satisfação do julgado, de um modo geral, já constitui um ato ilícito. E' principalmente na execução que o devedor, em desespêro de causa, vale-se da malícia, "numa conduta tergiversatória, natural nesse período judiciário, para êle tão doloroso e nefasto" (Mortara - Comm. V/118).

"As objeções e as exceções que no juízo da execução podem ser levantadas deduzir-se-ão tôdas elas no juízo da "oposição" (os nossos embargos), não devendo permitir-se que, rejeitado um motivo, um outro venha depois ser alegado. Não fica ao arbítrio da parte protrair indefinidamente o processo executivo, a que a lei imprime tôda trair indefinidamente o processo executivo, a que a lei imprime toda, (Ricci-Comm. III/61)",

O direito de retenção está, pois, sujeito a reconhecimento prévio, pela sentença exeqüenda, de existência de benfeitorias, ou, ao menos, essa alegação de benfeitorias deve vir, desde logo, acompanhada e amparada por alguma prova. Nessa hipótese, sim, pode o executado, segurando o juízo, pedir a retenção por benfeitorias, a teor do art. 1012, combinado com o $\$$ único do art. 996, ambos do Código de Processo Civil. E tanto isso é verdade que o $\$$ único do art. 996 prevê justamente a entrega ao exeqüente, exigindo, porém, dêste o depósito do 
valor das mesmas, arbitrado por perito judicial. Ora, para que tal se dê, é preciso que exista prova delas e de seu valor.

Prova delas existirá, por exemplo, quando a sentença exequienda já as reconheça como feitas pelo executado, ou, como na hipótese, a pontada por DE PLÁCIDO E SILVA, de benfeitorias pelo inquilino, "se tivesse havido expresso consentimento do proprietário com prova in-

Absurdo seria, pois, admitir tal discussão, quando a sentença exeqüenda não falasse em benfeitorias, quando nunca tivessem elas sido objeto de debate, nem, quiçá, de simples alusão, como, por exemplo, na hipótese de, na ação principal, ter limitado o réu sua defesa à alegação de usucapião.

Portanto, não havendo, na sentença exeqüenda, nada que se refira a benfeitorias, não poderá o executado, nos embargos, fazendo mera alegação das mesmas, desacompanhada de qualquer prova, pedir o direito de retenção, o qual, aliás, está subordinado à prévia segurança do juízo.

O Prof. ARNOLDO MEDEIROS DA FONSECA, catedrático da Faculdade de Direito da Universidade do Brasil, em sua magistral monografia sôbre $O$ Direito de Retenção, na qual fêz u’a mảgnífica construção jurídica relativa a êsse tão difícil e pouco estudado instituto do direito privado, enquadrando-o, em certos casos, como direito real, considera normas fundamentais para a teoria geral do direito de retenção as contidas nos artigos 516 e 873 do Código Civil, por êle assim explanadas:

"Dispõe o primeiro que todo o possuidor de boa-fé tem direito à indenização das benfeitorias necessárias ou úteis, podendo, pelo valor delas, exercer o direito de retenção. Prescreve o segundo, com generalidade, ao tratar das obrigações de restituir coisa certa, que, se a coisa tiver melhoramento ou aumento em conseqüência de trabalho ou dispêndio do devedor, vigorará o disposto no artigo 516 " (16).

Passa então a apontar os casos em que o direito de retenção é expressamente garantido no Código Civil, sob determinadas condições, isto é, ao credor pignoratício (arts. 772, alínea 2.a , e 773), ao depositário (art. 1279 e $\S$ único), no caso de depósito necessário (arts. 1282 e 1283), ao mandatário (art. 1315), ao marido (art. 260), ao locatário (art. 1199), ao possuidor de má-fé (art. 517) ( ${ }^{17}$ ).

Enumera em seguida os casos no campo do direito mercantil: Cod. Com., arts. 96, 97, 116, 117, 156, 189, 190, 216, 632; dec. n. ${ }^{\circ}$

15) DE PLÁCIDO E SILVA, o. C ,,vol. V. n. ${ }^{\circ} 2669, \mathrm{pg} .1999$

(16) ARNOLDO MEDEIROS DA FONSECA, O Direito de Retenção, n.o 102,
164-165. p.s. 164-165.

No direito precodificado, o fundamento do direito de retenção por benfeitorias era o disposto na Ord. L $\mathrm{L}^{0} 4$, tit. $54, \& 1 .^{\circ}:$ "E \&e o que vercebeu a cousa emprestada, aluter em si a dita cousa, fêz nela algumas despesas necessárias, ou proveitosas, poderá re-

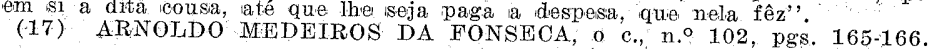

1102, de 21 de novembro de 1903, art. 14; Nova Consolidação das Leis das Alfândegas, de 1894 , art. 239; lei n. 1746 , de 13 de outubro de 1869 , art. $1 .^{\circ}, \S 12$; dec. n. ${ }^{\circ} 19473$, de 10 de dezembro de 1930 , art. $2^{\circ}$, n. ${ }^{\circ} \mathrm{VII}$, in fine, modificado pelo dec. n. ${ }^{\circ} 19754$, de 18 de março de 1931 , art. $10^{\circ}$; dec. n. ${ }^{\circ} 21081$, de 19 de outubro de 1932 , art. 40 ; decreto n. ${ }^{\circ} 5746$, de 9 de dezembro de 1929 (lei de falências), arts. 92, n. ${ }^{\circ}$ II, e $93, \S \$ 1 .^{\circ}$ e $3 .^{\circ}\left({ }^{18}\right)$.

Quanto à observação de CARVALHO SANTOS de que "eqüivaleria a tornar ilusório o direito de retenção assegurado na lei civil" o exigir prévia segurança do juízo, opomos a consideração de que o Código de Processo Civil inovou algo em matéria de retenção.

O Prof. ARNOLDO MEDEIROS DA FONSECA, em sua citada monografia, escrevera:

"Advirta-se, de início, que o juíz não tem poder de atribuir direito de retenção a quem quer que seja; cabe-lhe apenas declarar se a retenção exercida é justa ou injusta, legal ou ilegal" $\left({ }^{19}\right)$.

Assim ensinava o eminente mestre, em face da lei substantiva e dos Códigos processuais então vigentes.

No entanto, o Código de Processo Civil, em 1939, inovou na matéria pelo preceito do art. 1012.

Mesmo que se considere de direito material e não formal, ainda assim, válida é a reforma da lei substantiva, porque o legislador tinha, constitucionalmente, competência para tanto, embora passível de censura por defeito de técnica jurídica. Daí, a verdadeira invasão que o Código de Processo Civil operou em várias matérias de Direito Civil, verbi gratia, consagrando expressamente, no art. 552, o fideicomisso por ato inter vivos, até então objeto de viva controvérsia $\left({ }^{20}\right)$, e regulando prescrição (art. 166, $\$ \S 2 .^{\circ}$ e $3 .^{\circ}$ ), Registro Torrens (art. 457), sub-rogação de bens inalienáveis (art. 629), frutos de bens inalienáveis (art. 943, n. ${ }^{\circ}$ 1), procurações judiciais (arts. 107 e 108), criando anticrese judicial (art. $982, \$ 2 .^{\circ}$ ), etc., principalmente quando se entrosam preceitos de carácter formal com os de natureza material.

O art. 1012 do Código de Processo Civil regulamentou o art. 516 do Código Civil e, eliminando qualquer incerteza, disciplinou o exercício do direito de retenção, quando já ajuizada a execução duma ação real, subordinando-o à exigência de pedido, por parte do executado,

(18) Releva observar que, como já tivemos ocasião de acentuar a propósito de 7.661 , de 21 de junho de 1945), adotando o osistema de sòmente coordenar "a matéria própria da falência com as disposiçôs das leis civis e comericiais e das leis especiais (exposição de motivos, ut DIÁRIO OFICIAL, de 31 de julho de 1945 , suplemento, pg. 15), apenas se refere ao direito de retenção no art. $102, \& 2 .^{\circ}$, n.o III.

(19) ARNOLDO MEDETROS DA FONSECA, o. c., n.o 162, pg. 288.
(20) ARMANDO DIAS DE AZEVEDO, Do fideicomisso, n. ${ }^{\circ} 62.77$, pgs, 46.59 
de retenção por benfeitorias ( $\left.{ }^{21}\right)$, pedido êsse que deve ser exercido por via de embargos (arts. 992 e 996), mas só depois de seguro o juizo (art. 995).

Êsse exercício do direito de retenção - repetimos - só será admissível com prova preexistente, por exemplo, quando a própria sentença exeqüienda já reconheça a existência de benfeitorias do vencido, a par de sua boa fé, ou quando, em escrito firmado pelo exeqüente, tivesse sido o executado autorizado a realizá-las, etc.

Talvez causem estranheza nossas considerações sôbre o alcance do disposto no art. 996 do Código de Processo Civil, depois de corrigido, mas reputamos inteiramente oportunas, em face de correrem mundo comentários a textos modificados pelo decreto-lei n. 4.565 , portanto, textos legais revogados, de que se valem, por vêzes, advogados inadvertidos de tais alterações tão profundas, e, em certos casos, fundamentais, estabelecidas por leis extravagantes posteriores, àquela época, de tão fácil e abundante produção e, não raro, de tão difícil interpretação.

(21) Dissertando sôbre a exceção e as relaçóes com os direitos de impugnação de Direito da Universidade de Montevideo:

"Assim, por exemplo, a compensação, a direito de retenção, a exceptio inadimpleti contractu, configuram outras tantas situaçóes nas quais o réu poderia propor contra o
autor uma acão autônoma. Tendo êle a faculdade de prov ouñ autor uma ação autônoma. Tendo ele a faculdade de propor ou não essisa ação, e não tar que essas mesmas situacốes, quando utilizadas acomo excecốes sòmente lógico suste invocadas por pieticão da parte", (EDUARDO J. COUTURE, Fundamentos do Direito rocessual Oivit, n. $27, \mathrm{pg} .65)$.

" A respeito da natureza do direito de retenção assim escreve COVIELLLO

um derecho, sino simplemente un medio de tutela de un derechio de credito, no es siquiera dilatoria; lo cual se comprueba por su derivación histórica de la exceptio doli generatis, y por su funcionamento práctico" (COVIELLO, Doctrina general del Derecho, n. ${ }^{\circ} 166$,

O DIREITO INDUSTRIAL NA VIDA E NA

\section{OBRA DE RUY BARBOSA}

\section{Dario de Bittencourt}

I-Preâmbulo. - II. Direito Industrial - emancipação do Direito Mercantil; conceito e campo de aplicação. - III. A Constituição do Império (1824) aplicação. - IIT. Aíéo dos inventores. - IV. O Cóe a tutela ao privilégio do 28 de agôsto de $1830 .-V$. digo Criminal e a lei de 28 de agôsto de 1830 . - Vmissá legal de normas protetoras das marcas de industria. VII. A contrafação da marca "Rapé Arêa Preta", na Baia, e o trabalho do jovem advogado Ruy Barbosa, no fôro e na imprensa. - VIII. A atuação do deputado Ruy Barbosa: a) votos em contrário à concessão de privilégios; b) contra o privilégio para fabricacão do sulfureto de carbono $(1880)$; c) parecer fabricação do sulfureto de carbono (1880) lei sôbre o e redação final do projeto de reforma dX. Desenho inprivilégios de invenção (1880). - IX. Desenho in dustrial e arte aplicada (1882). - X. A elaboração do Código Civil e a Propriedade Industrial. - XI. A crítica de Ruy Barbosa. - XII. As cessões de clientela e um pleito sôbre concorrência desleal. clientela e um pleito sobre concorrencia desclusão).

$$
-1-
$$

1. Felicíssima, incontestàvelmente, a resolução há tempos tomada pela douta Congregação da FACULDADE DE DIREITO DE PÔRTO ALEGRE, no sentido de, na semana consagrada às comemoPORTO ALEGRE, no sentios namento de Ruy Barbosa, realizar cada rações pelo centenário do nascimento de Ruy Barbosa, reando os asprofessor, perante a própria classe, uma dissertação versando os aspectos da obra do insigne brasileiro e que tivessem correlação com a respectiva disciplina. 